\title{
Reflux related symptoms in patients with normal oesophageal exposure to acid
}

\author{
G Shi, S Bruley des Varannes, C Scarpignato, M Le Rhun, J-P Galmiche
}

\begin{abstract}
Several studies, using pH monitoring with event markers, have identified patients with normal oesophageal exposure to acid despite an apparent relation between symptoms and refiux episodes. In this series of 771 consecutive patients referred for 24 hour oesophageal pH monitoring, a probability calculation was used to evaluate the relation between symptoms and reflux episodes. Oesophageal exposure to acid was normal in 462 of 771 recordings (59.9\%); despite this, $70.8 \%$ (327 of 462) of these patients used at least once the event marker. In 96 patients (12.5\% of total patients) with normal oesophageal exposure to acid, there was a statistically significant association between symptoms and reflux episodes. The symptom cluster of such patients was similar to that usually seen in patients with gastro-oesophageal reflux disease, but symptoms like belching, bloating, and nausea were common thus overlapping with the symptom pattern of functional dyspepsia. In these patients both the duration and the minimum $\mathrm{pH}$ of reflux episodes (either symptom related or asymptomatic) were significantly shorter and higher, respectively, when compared with those of patients with gastrooesophageal reflux disease. These results are consistent with the idea that oesophageal hypersensitivity to acid is the underlying pathophysiological feature of this syndrome.

(Gut 1995; 37: 457-464)
\end{abstract}

Gastroenterology and

Hepatology, University

of Nantes, France

G Shi

$S$ Bruley des Varannes

$M$ Le Rhun

J-P Galmiche

Institute of

Pharmacology, School

of Medicine and

Dentistry, University

of Parma, Italy

C Scarpignato

Correspondence to: Professor J-P Galmiche, Laboratoire Fonctions

Digestives et Nutrition,

CHU Nord, 44035 Nantes

Cedex, France.

Accepted for publication

16 February 1995
Keywords: pH monitoring, gastro-oesophageal reflux, symptom reflux relations, visceral perception.

Ambulatory oesophageal $\mathrm{pH}$ monitoring is currently regarded as the most objective means for detecting and quantifying gastrooesophageal reflux. It also represents the most sensitive diagnostic investigation for gastrooesophageal reflux disease. ${ }^{1}$ The availability of modern portable data loggers with one or more event markers has permitted a better understanding of the relations between symptoms and reflux episodes occurring during 24 hour oesophageal $\mathrm{pH}$ monitoring. When the relation of oesophageal exposure to acid with symptoms is considered, four possibilities exist - that is, abnormal oesophageal exposure to acid with or without temporal relation between symptoms and reflux episodes and normal oesophageal exposure to acid without or with temporal relation between symptoms and reflux episodes.

Patients with both normal oesophageal exposure to acid and apparent temporal relation between symptoms and reflux episodes have been identified in several studies, including ours. ${ }^{2-10}$ Some indices have been proposed to assess the strength of this relation, including symptom specificity index ${ }^{10-13}$ and symptom sensitivity index..$^{13}$ Unfortunately, cut off values of these indices have been chosen arbitrarily and often differ from one study to another. In addition, it should be considered that some symptoms may occur simultaneously with reflux episodes only by chance. To overcome these limitations, Ghillebert et $a l^{14}$ recently proposed the evaluation of the relation between symptoms and reflux episodes by using a probability calculation based on the binomial law. Although not perfect in theory, this method has the advantage of describing that strength of the association without any previous arbitrary choice. In fact, the association can be regarded as significant if the $p$ value is less than the generally accepted value of $5 \%$.

We have recently adopted this method to calculate the probability that symptoms and reflux episodes occur simultaneously only by chance in a large series of consecutive patients referred to our laboratory for 24 hour oesophageal $\mathrm{pH}$ monitoring. Among this large number of subjects, we identified a subset of patients characterised by normal oesophageal exposure to acid and a significant association between symptoms and reflux episodes who seem to have an 'acid hypersensitive oesophagus'. In this study we therefore tried to define the frequency of the acid hypersensitive oesophagus syndrome and its main clinical picture, and to compare - in patients with both normal and abnormal oesophageal exposure to acid - the results obtained with probability calculation with those derived from previously described symptom indices. During these studies, the reproducibility of $\mathrm{pH}$ monitoring in the evaluation of symptom reflux relations was also assessed. 


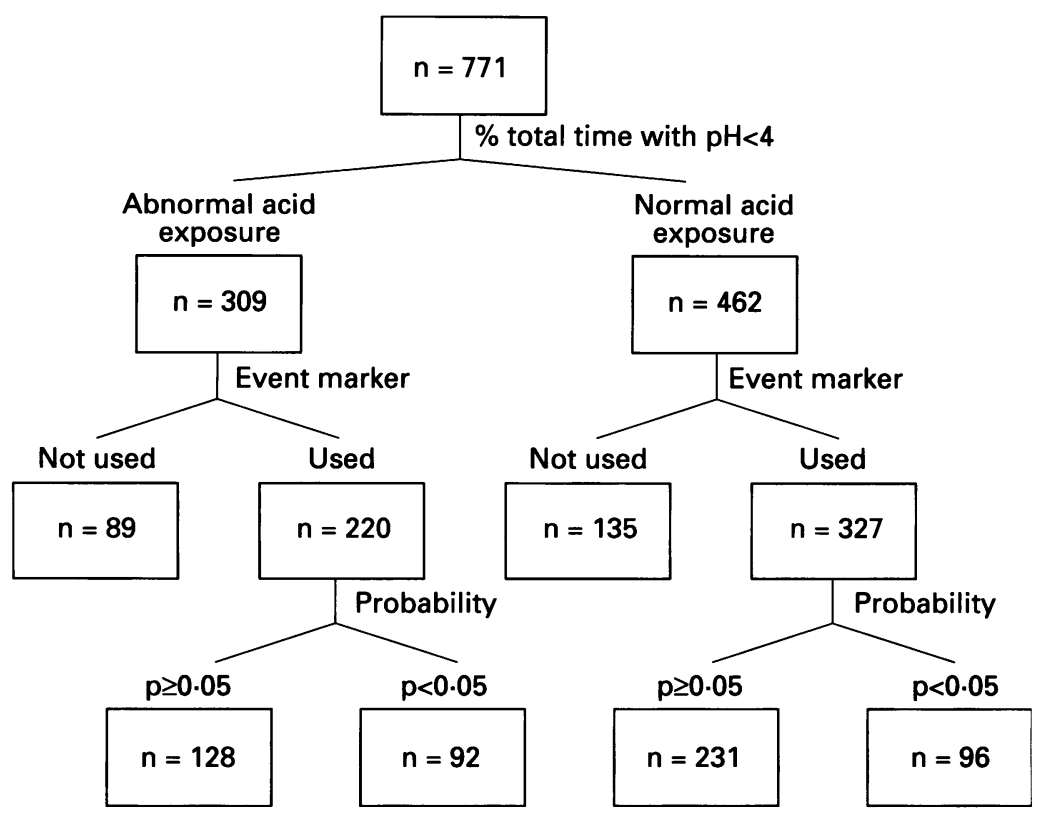

Figure 1: Frequency of patients with normal oesophageal exposure to acid and statistically significant association between symptoms and reflux episodes during 24 hour $p H$ monitoring among a series of 771 consecutive patients referred for 24 hour pH monitoring. Some patients were investigated on several occasions. ( $n=n u m b e r$ of patients.)

\section{Methods}

\section{Patients}

A total of 771 consecutive patients (392 men and 379 women, age $50 \cdot 4(14 \cdot 8)$, mean (SD)) were submitted to 24 hour $\mathrm{pH}$ monitoring because of symptoms suggestive of gastrooesophageal reflux disease or non-cardiac chest pain, or both, during the period January 1989-June 1993 (Fig 1). Some patients were studied on several occasions to evaluate the reproducibility of each proposed parameter for assessing the symptom reflux relations.

\section{Endoscopy}

Upper digestive endoscopy was performed on an outpatient basis on subjects fasted overnight. A complete examination of the oesophagus, stomach, and duodenum was achieved. Oesophagitis was graded as follows: grade 1 isolated erosions, grade 2 confluent erosions or ulcerations (not circumferential), and grade 3 circumferential lesions. Patients with stricture or Barrett's oesophagus were not included in the study.

\section{Twenty four hour $\mathrm{pH}$ monitoring}

Twenty four hour oesophageal $\mathrm{pH}$ recording was performed using a combined glass $\mathrm{pH}$ electrode (440M4, Ingold, Urdorf, Switzerland) and a digital data logger (Digitrapper MKII, Synectics, Stockholm, Sweden). The system was calibrated at $\mathrm{pH} 1$ and $\mathrm{pH} 7$ before each study. The patients fasted for at least 12 hours and had stopped taking any antireflux treatment (that is, antisecretory or prokinetic drugs, or both), which can interfere with the results. The probe was passed through the nose and positioned $5 \mathrm{~cm}$ above the upper border of the gastro-oesophageal junction, which was determined either by previous manometry or by the
pH step up method. ${ }^{1}$ During early studies, $\mathrm{pH}$ monitoring was performed in the hospital setting under standardised conditions. More recently (the last 82 cases), studies were performed on an outpatient basis in fully ambulatory conditions - that is, without any dietary restriction except for food and beverages with a $\mathrm{pH}<5$. Periods of eating, drinking, and supine position were specified by patients on a diary card. At the start of the recording, patients were carefully instructed to press the event marker button if they had a symptom. This recommendation was also emphasised on the diary card.

After the 24 hour $\mathrm{pH}$ monitoring, the data were downloaded from the digital data logger to an IBM computer and the recorded data were analysed by using a dedicated software (EsopHogram 5.5) written by Gastrosoft (Dallas, USA). Apart from the usual reflux parameters (\% time below $\mathrm{pH} 4$ and characteristics of reflux episodes), three indices were calculated to measure the strength of the relation between symptoms and reflux episodes: the probability that symptoms and reflux episodes occurred simultaneously by chance, ${ }^{14}$ the symptom specificity index, ${ }^{1012}$ and the symptom sensitivity index. ${ }^{13}$ For the evaluation of the temporal relation between symptoms and reflux episodes, $\mathrm{pH}$ tracings were reviewed and a symptom and a reflux episode were considered causally related if a symptom occurred during the reflux episode itself or within two minutes after it finished.

The probability (p) that symptoms and reflux episodes occurred simultaneously by chance was obtained by summing a number of partial probabilities, each of which was obtained by using the binomial formula, described later ${ }^{14}$ :

$$
\frac{n !}{r !(n-r) !} p^{r}(1-p)^{n-r}
$$

where $\mathrm{n}$ is the total number of symptom episodes signalled by the patient; $r$ ranges from the actual number of symptom episodes that occur during or within two minutes of the end of a fall in $\mathrm{pH}$ below 4 to $\mathrm{n} ; \mathrm{p}$ is the probability that one symptom episode occurs during or within two minutes of the end of a fall in $\mathrm{pH}$ below 4 only by chance and is calculated from the formula:

$\mathrm{p}=$ total time $(\mathrm{min}) \mathrm{pH}$ below $4+(2 \min \times$ number of $\mathrm{pH}$ drops below 4$)$ Total time ( $\mathrm{min}$ ) of recording

The symptom specificity index, which determines the percentage of reflux related symptom episodes, was calculated as described by Wiener et al ${ }^{10}$ whereas the symptom sensitivity index, which calculates the percentage of symptom related reflux episodes was quantified according to Breumelhof and Smout. ${ }^{13}$

\section{Statistical evaluation of data}

The $\mathrm{pH}$ data are presented as median values with interquartile ranges. Student's $t$ test was used to compare the mean duration and minimal $\mathrm{pH}$ between the symptom related reflux episodes and the asymptomatic reflux 
TABLE I Clinical characteristics of 96 patients with normal oesophageal exposure to acid and statistically significant association between symptoms and reflux episodes during 24 hour $\mathrm{pH}$ monitoring

\begin{tabular}{lc}
\hline Age (mean and range, years) & $48 \cdot 8(18-73)$ \\
Sex (male/female) & $45 / 51$ \\
Predominant symptoms (\%) & $74 \cdot 4$ \\
Digestive symptoms & $4 \cdot 7$ \\
NCCP & $14 \cdot 0$ \\
Respiratory symptoms & $6 \cdot 9$ \\
ENT & $24 \cdot 0(0 \cdot 5-204)$ \\
Duration of symptoms (median and range, & \\
$\quad$ months) & $81 \cdot 1$ \\
Endoscopy (n=74) & \\
$\quad$ Normal mucosa (\%) & $14 \cdot 9$ \\
Oesophagitis (\%) & $2 \cdot 7$ \\
$\quad$ Grade 1 & $1 \cdot 4$ \\
$\quad$ Grade 2 & $37 \cdot 8$ \\
$\quad$ Grade 3 & \\
\hline
\end{tabular}

$\mathrm{NCCP}=$ non-cardiac chest pain; $\mathrm{ENT}=$ ear, nose, and throat.

episodes. Least squares regression analysis was used to calculate the correlation between the probability (-log) that symptoms and reflux episodes occurred simultaneously by chance, the symptom specificity index, and the symptom sensitivity index. A $p$ value $<0.05$ was considered significant.

\section{Results}

\section{Frequency and clinical characteristics}

Oesophageal exposure to acid was normal (total fraction time of $\mathrm{pH}$ below $4<4.2 \%$ ) in 462 patients $(59.9 \%$ of the whole patient's population); despite this, $70 \cdot 8 \%$ (327 of 462 ) of these patients used at least once the event marker (Fig 1). The symptoms reported by patients during 24 hour $\mathrm{pH}$ monitoring included heartburn, regurgitation, epigastric pain, epigastric burning, discomfort or noncardiac chest pain, or all of these. In 96 patients $(12 \cdot 5 \%$ of total patients) with normal oesophageal exposure to acid, there was a statistically significant association between symptoms and reflux episodes as previously defined (Fig 1). Five patients had two and one had three $\mathrm{pH}$ recordings with normal oesophageal exposure to acid and statistically significant association between symptoms and reflux episodes. Patients with normal oesophageal exposure to acid used more frequently the event marker when they were investigated outside rather than in the hospital setting ( $87 \% v 67 \%, \mathrm{p}=0.005)$. Accordingly,

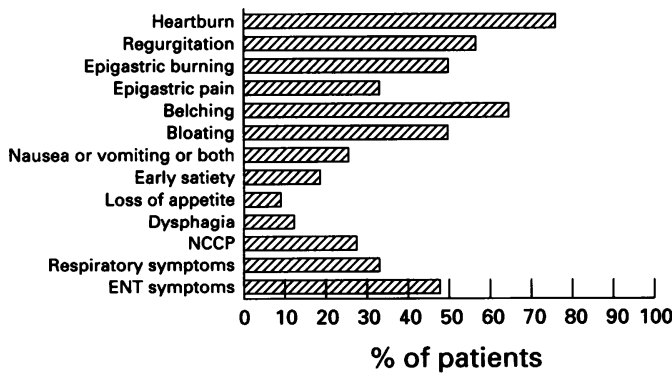

Figure 2: Frequency of the different symptoms seen in 96 patients with normal oesophageal exposure to acid and statistically significant association between symptoms and reflux episodes during 24 hour $\mathrm{pH}$ monitoring.

(NCCP=non-cardiac chest pain; $E N T=e a r$, nose, and throat). the frequency of the acid hypersensitive oesophagus syndrome was slightly but significantly higher when $\mathrm{pH}$ monitoring was performed in an outpatient basis $(20.7 \% v 10.9 \%$, $\mathrm{p}<0.01)$. Table I summarises the clinical characteristics of these patients. Seventy four of these patients also had upper gastrointestinal endoscopy within one month prior to $\mathrm{pH}$ monitoring.

The sex ratio (male/female) was not statistically different from that of the whole patient population (45 and $51 v 392$ and 379, NS) and from that of patients with normal oesophageal exposure to acid (45 and $51 v 209$ and 253, NS). Age of patients ranged from 18 to 73 years with mean value of 48.8 years, a figure virtually identical to that seen in the whole patient population $(48.8(14.3) v 50.4(14.8)$ years, NS) and to that seen in patients with normal oesophageal exposure to acid $(48 \cdot 8$ $(14.3) v 50 \cdot 8(14.9)$, NS).

Figure 2 shows the frequency of the different symptoms experienced by these 96 patients. With regard to typical symptoms of reflux, heartburn, regurgitation, and epigastric burning were reported by $76 \%, 57 \%$, and $50 \%$ of patients, respectively. Many patients also complained of belching $(68 \%)$, or dyspeptic symptoms (for example, bloating, nausea, vomiting, early satiety, loss of appetite), or both (Fig 2). Otherwise, non-cardiac chest pain, ear, nose, and throat symptoms, and respiratory symptoms were seen in $27.8 \%$, $47 \cdot 8 \%$, and $33.3 \%$ patients, respectively. The predominant symptoms (that is, the symptoms leading the patients to seek medical care) were digestive symptoms $(74.4 \%)$, respiratory symptoms $(14.0 \%)$, ear, nose, and throat symptoms $(6.9 \%)$, or non-cardiac chest pain $(4 \cdot 7 \%)$. The duration of symptoms ranged from 0.5 month to 17 years (median: 24 months). In those patients in whom endoscopy was performed, it mostly showed a normal oesophageal mucosa and a mild oesophagitis in most of the other patients (Table I).

Frequency of symptom episodes, reflux episodes, and reflux related symptom episodes

In the 96 patients, 1161 symptom episodes and 3306 reflux episodes were registered during the 24 hour $\mathrm{pH}$ monitoring. Five hundred and three of 1161 symptom episodes $(43.3 \%)$ were reflux related as previously defined. Forty three patients $(44 \cdot 8 \%)$ had more than four reflux related symptom episodes. Table II shows the results of $\mathrm{pH}$ monitoring in the 96 patients.

Probability, symptom specificity index, and symptom sensitivity index

Figure 3 shows the distributions of probability (-log), symptom specificity index, and symptom sensitivity index in patients with acid hypersensitive oesophagus syndrome. The probability was $<0.01$ in 71 patients and $<0.001$ in 41 patients (Fig 3A). Nine patients had a symptom specificity index lower than $25 \%$, 48 patients equal or greater than $50 \%$, 
TABLE II Results of 24 hour pH monitoring in 96 patients with normal oesophageal exposure to acid and statistically significant association between symptoms and reflux episodes during 24 hour $\mathrm{pH}$ monitoring

\begin{tabular}{lccc}
\hline & $\begin{array}{l}\text { Median } \\
\text { values }\end{array}$ & $\begin{array}{l}\text { Interquartile } \\
\text { range }\end{array}$ & $\begin{array}{l}\text { Upper limit of reference } \\
\text { values of our laboratory }\end{array}$ \\
\hline \% Total & $2 \cdot 0$ & $1 \cdot 1-3 \cdot 1$ & $4 \cdot 2$ \\
$\%$ Upright & $2 \cdot 6$ & $1 \cdot 6-4 \cdot 5$ & $8 \cdot 0$ \\
\% Supine & $0 \cdot 3$ & $0 \cdot 0-1 \cdot 4$ & $3 \cdot 0$ \\
Total episodes (n) & 28 & $20-41$ & 50 \\
Episodes >5 min (n) & $1 \cdot 0$ & $0-1 \cdot 0$ & 3 \\
Longest episodes (min) & $5 \cdot 0$ & $3 \cdot 0-7 \cdot 5$ & 20 \\
\hline
\end{tabular}

and 23 patients equal or greater than $75 \%$ (Fig 3B). The symptom sensitivity index was $\geqslant 10 \%$ in 70 patients and $\geqslant 20 \%$ in 38 patients (Fig 3C). When symptom specificity index and symptom sensitivity index were considered together, it was found that $33(34 \cdot 4 \%)$ patients had a symptom specificity index $\geqslant 50 \%$ with a symptom sensitivity index $\geqslant 10 \%$. No patient had a symptom specificity index $<25 \%$ and a symptom sensitivity index $<10 \%$.

There was a poor albeit significant $(\mathrm{p}<0.05)$ correlation between probability $(-\log )$ and symptom specificity index in both patients with acid hypersensitive oesophagus syndrome and with gastro-oesophageal reflux disease (Fig 4A and Fig 5A). In contrast, a strong and significant $(p<0.0001)$ correlation was seen between probability (-log) and symptom sensitivity index (Fig 4B and Fig 5B). As expected, symptom specificity index and symptom sensitivity index were inversely related to each other (Fig 4C), but the correlation in patients with gastro-oesophageal reflux disease (Fig 5C) fell short off statistical significance.

\section{Characteristics of reflux episodes}

Table III shows mean duration and minimum $\mathrm{pH}$ of symptom related reflux episodes and asymptomatic reflux episodes in patients with acid hypersensitive oesophagus syndrome and those with gastro-oesophageal reflux disease. Symptom related reflux episodes had significantly longer duration $(p<0.001)$ than the asymptomatic ones in total time and upright position, but not in supine position $(p>0.05)$. Similarly, the minimum $\mathrm{pH}$ of symptom related reflux episodes was lower than that of asymptomatic ones in total time and upright position $(p<0.001)$, but not in supine position $(p>0.05)$. When the characteristics of symptom related (as well as asymptomatic) reflux episodes of patients with acid hypersensitive oesophagus syndrome were compared with those of patients with true gastro-oesophageal reflux disease, both the duration and minimum $\mathrm{pH}$ of the first group were significantly shorter and higher than those of the second, respectively.

\section{Reproducibility of $\mathrm{pH}$ monitoring in the assessment of symptom reflux relations}

During the study period, 13 of 96 patients were studied on at least two occasions by 24 hour $\mathrm{pH}$ monitoring. The median interval between the two $\mathrm{pH}$ recordings was 12 months (range 1-47 months). Despite this sometimes long interval between assessments, these patients always experienced nearly the same symptoms and used at least once the event marker during each of the $26 \mathrm{pH}$ monitoring. In six of these 13 patients, the diagnosis of acid hypersensitive oesophagus syndrome - that is, patients with normal oesophageal exposure to acid and symptom related reflux episodes - was consistently made. In seven other patients, only one recording showed the pattern of acid hypersensitive oesophagus syndrome (Table IV). Nine patients had normal oesophageal exposure to acid during the two $\mathrm{pH}$ recordings. Ten patients had a significant relation between symptoms and reflux episodes on both recordings but four of them had a discrepancy for oesophageal acid exposure between the two $\mathrm{pH}$ recordings (Table IV). Oesophageal exposure to acid never exceeded $6.7 \%$ of the total time, however, and, albeit abnormal, it always remained very close to the upper limit of normality $(4 \cdot 2 \%)$.

\section{Discussion}

Although traditional $\mathrm{pH}$ metric variables (total reflux time, the total number of refluxes, and the number of refluxes longer than five
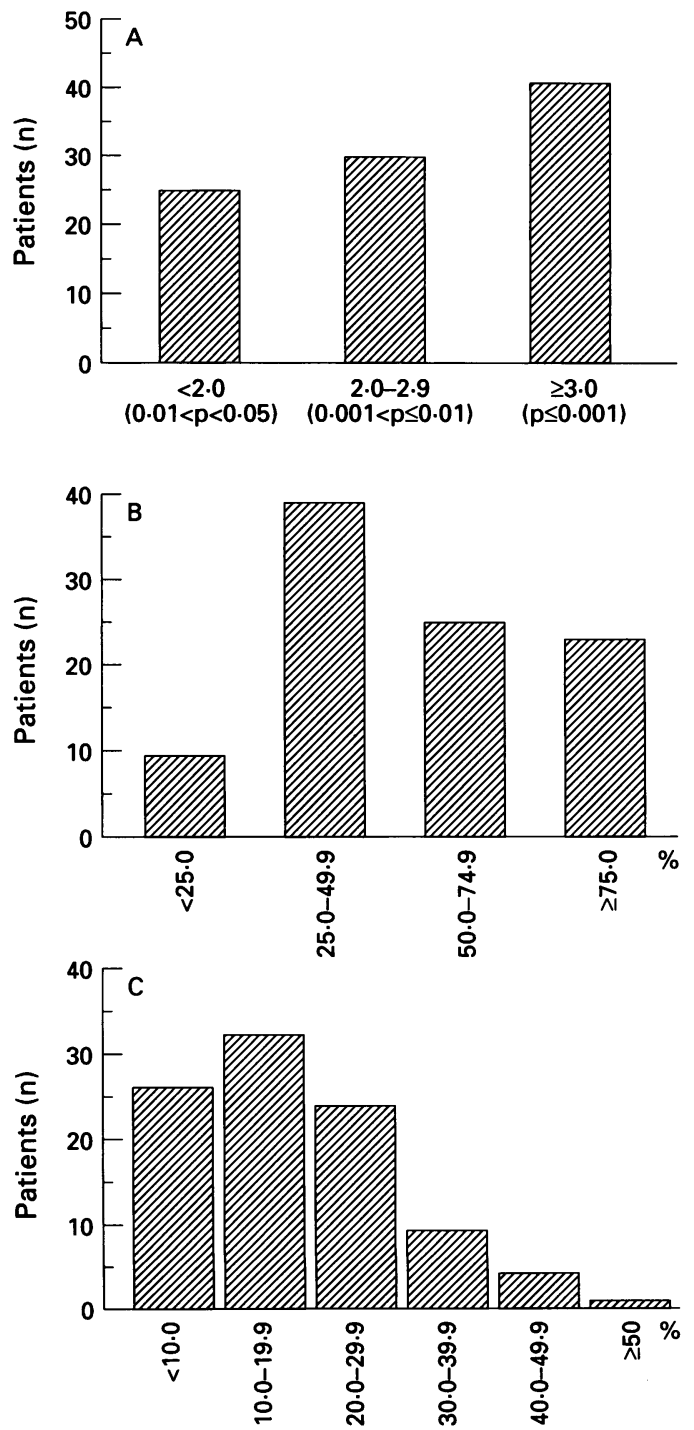

Figure 3: Distribution of probability $(-\log )(A)$, symptom specificity index $(B)$, and symptom sensitivity index $(C)$ in 96 patients with normal oesophageal exposure to acid and 96 patients with normal oesophageal exposure to acid and reflux episodes during 24 hour $\mathrm{pH}$ monitoring. 
minutes) still remain useful parameters to discriminate between patients with gastrooesophageal reflux disease and asymptomatic healthy subjects, they do not help in establishing any responsibility for acid reflux in the patient's complaints. The use of the event marker(s) or diary card, or both, is mandatory to show a temporal relation between symptoms and reflux episodes. However, not only could symptoms be unrelated to reflux episodes in the presence of abnormal oesophageal exposure to acid, but also, conversely, a symptomatology that apparently reflux related can be seen in patients whose oesophageal exposure to acid is normal. Although several studies have been able to identify patients with normal oesophageal exposure to acid and acid related symptoms, ${ }^{2-10}$ the exact frequency of this acid hypersensitive oesophagus syndrome and its symptom pattern have not been established, as yet.
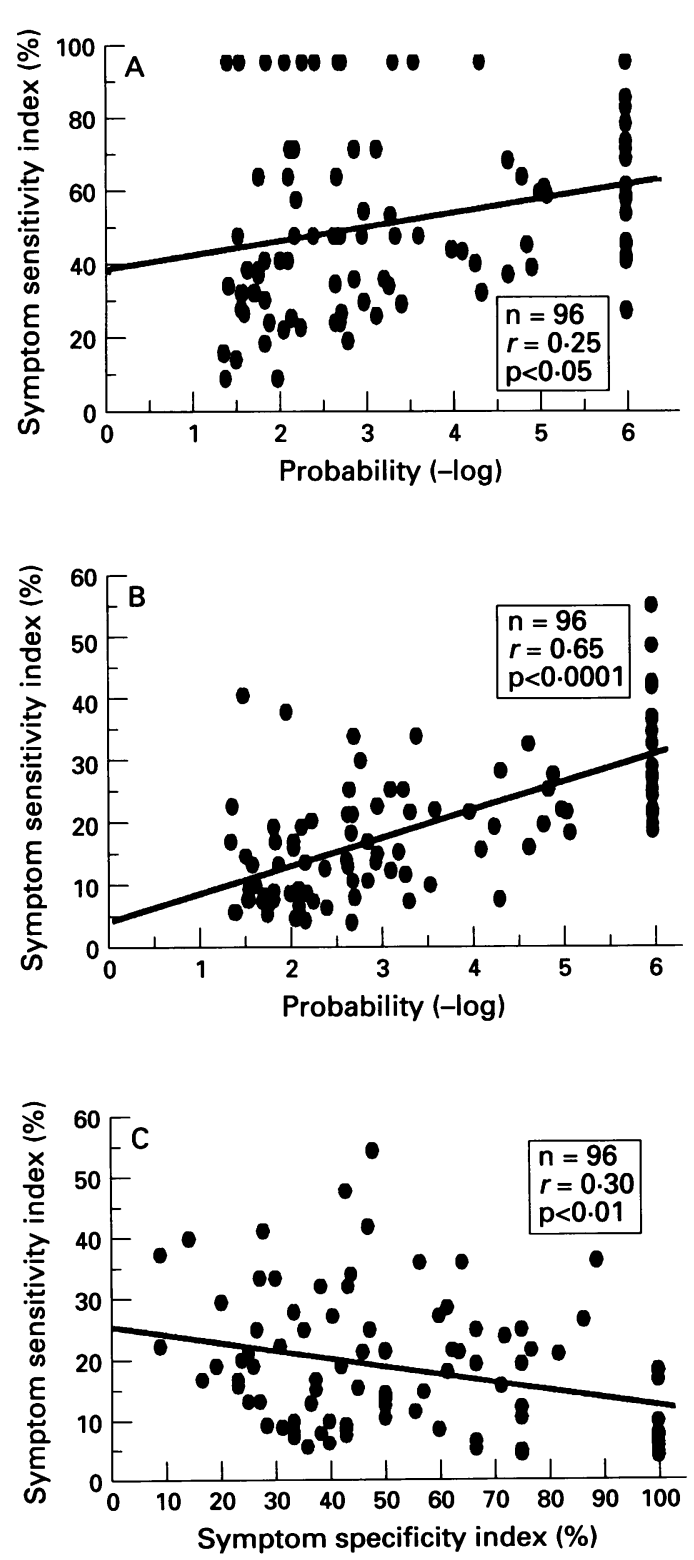

Figure 4: Correlations between probability (-log) and symptom specificity index $(A)$, probability $(-\log )$ and symptom sensitivity index (B), and symptom specificity index and symptom sensitivity index $(C)$ in 96 patients with normal oesophageal exposure to acid and statistically significant association between symptoms and reflux episodes during 24 hour $\mathrm{pH}$ monitoring.
While analysing symptom reflux relations, two important limitations should be taken into account. Firstly, according to our own experience $^{2}$ only half of the patients used the event marker and in only $50 \%$ of the cases are symptoms perceived by the patients reflux related. Performing 24 hour $\mathrm{pH}$ monitoring outside the hospital setting could improve the diagnostic yield of the technique as shown in this study. Secondly, there is no uniform agreement on how to measure the strength of association between symptoms and reflux episodes. Indeed, although some indices are currently used, different cut off values are used by different groups of investigators. As symptoms may occur simultaneously with reflux episodes only by chance, a more scientifically sound approach could be the one recently described by Ghillebert et al, ${ }^{14}$ which is based on probability calculation. In our investigation we have therefore adopted this approach to
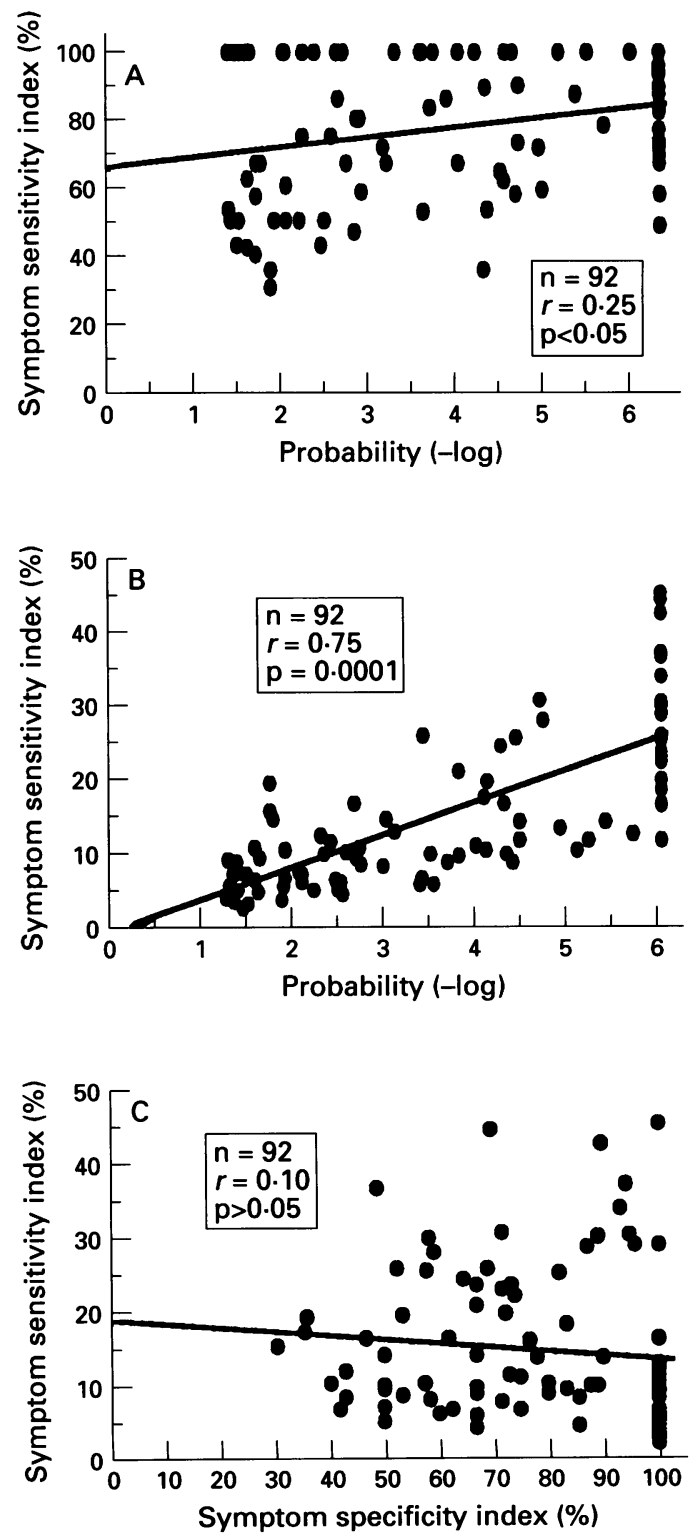

Figure 5: Correlations between probability (-log) and symptom specificity index $(A)$, probability $(-\log )$ and symptom sensitivity index $(B)$, and symptom specificity index and symptom sensitivity index (C) in 92 patients with abnormal oesophageal exposure to acid and statistically significant association between symptoms and reflux episodes during 24 hour $\mathrm{pH}$ monitoring (that is, with gastro-oesophageal reflux disease). 
The symptom cluster of patients with acid hypersensitive oesophagus syndrome is similar to that usually seen in patients with gastrooesophageal reflux disease, but symptoms like belching, bloating, and nausea are common thus overlapping with the symptom pattern of functional dyspepsia. As most patients with reflux related symptoms but with normal oesophageal exposure to acid had a normal oesophageal mucosa at endoscopy (and the remaining only a mild oesophagitis), they should represent the patients with true reflux like dyspepsia. What indeed has been classified as reflux like dyspepsia ${ }^{18}$ is actually gastrooesophageal reflux disease, which encompasses reflux oesophagitis, that is gastro-oesophageal reflux with unequivocal changes within the oesophagus and non-erosive gastro-oesophageal reflux disease - that is, symptomatic reflux proved by objective means, without changes being demonstrated.

The exact mechanisms by which reflux causes oesophageal symptoms are still poorly understood and it is unknown whether symptoms arise directly through activation of chemoreceptors ${ }^{19}$ or, indirectly, as a result of motility disturbances or mechanical distension of the oesophagus secondary to reflux. It is now well established, however, that, in patients with gastro-oesophageal reflux disease, about $80 \%$ of reflux episodes are symptom free, regardless of the severity of oesophageal lesions. ${ }^{20}$ Why some reflux episodes are perceived by the patient and some others are not is also unknown. In agreement with Baldi et $a^{20}$ and Smith et $a l^{21}$ who studied small series of patients with reflux oesophagitis, we found that symptom related reflux episodes lasted longer than those not perceived by the patient. In addition, both the duration and the minimum $\mathrm{pH}$ of reflux episodes (either symptom related or asymptomatic) were significantly shorter and higher, respectively, in patients with acid hypersensitive oesophagus syndrome when compared with those of patients with 'classic' gastro-oesophageal reflux disease. These data clearly suggest the presence of 'hypersensitivity' to acid in the first group of patients.

Results of our investigation are consistent with the idea that acid contact time is one important contributing factor to oesophageal sensitivity. The $\mathrm{pH}$ of refluxate also seems to be a critical factor in the perception process. Indeed, we were able to show that when reflux episodes were perceived, $\mathrm{pH}$ dropped to a value that was significantly $(p<0.001)$ lower than that seen with asymptomatic reflux episodes. And this is true for both acid hypersensitive oesophagus and gastro-oesophageal reflux disease patients. Why the comparatively short lasting (1.28 (0.08) min) and less acidic reflux episodes occurring in the subset of patients with normal oesophageal exposure to acid are perceived still remains unclear. Factors other than acidity can result in an increased pain perception, including volume of the refluxate and non-acidic components. Whether an increased sensitivity to mechanical stimuli is an additional pathophysiological feature of these patients, as described by Janssens and Vantrappen ${ }^{22}$ in non-cardiac chest pain patients with the so called irritable oesophagus syndrome,' is presently unknown.

If the assumption is accepted that, despite lack of mucosal injury, patients with acid hypersensitive oesophagus syndrome have an increased oesophageal perception as underlying cause, therapeutic effort should be directed to reduce such increased sensitivity. Unfortunately, not all available drugs (namely 5- $\mathrm{HT}_{3}$ antagonists and opioids), capable of reducing visceral perception in the lower gastrointestinal tract, seem to be effective in the upper gastrointestinal tract. ${ }^{23}$ Therefore, reduction of the stimulus intensity remains at present the only alternative in clinical practice. Provided that the acid is the major stimulus, antisecretory compounds should be the drugs of choice. The reported finding of a reduction of oesophageal sensitivity by famotidine in gastro-oesophageal reflux disease patients ${ }^{24}$ suggests that $\mathrm{H}_{2}$ blockers, besides reducing acid secretion, might interfere with the neural pathways controlling visceral perception and give a further rationale for the use of this class of drugs in such a subset of patients.

We are grateful to M F Courjal and B Beignet for their expert technical assistance. This work was partially supported by a grant from the Centre Hospitalier Universitaire of Nantes.

Preliminary data of the present investigation have been presented at the American Gastroenterological Association (San Francisco) and appeared in abstract form (Gastroenterology 1992; 102: A45)

1 Galmiche JP. Scarpignato C. Esophageal pH monitoring. In: Scarpignato C, Galmiche JP. Functional investigation in esophageal disease. Front Gastrointest Res. Basel: Karger, 1994; 22: 71-108.

2 Barré P, Bruley des Varannes S, Masliah C, Cloarec D, Le Bodic L, Galmiche JP. Le marqueur d'événements: un progrès dans l'interprétation de la $\mathrm{pH}$-métrie oesophagienne. Gastroenterol Clin Biol 1989; 13: 32-7.

3 Bruley des Varannes S, Le Rhun M, Simon J, Galmiche JP. The acid hypersensitive esophagus: a frequent cause of symptoms in patients with normal esophageal acid exposure (EAO)? Gastroenterology 1992; 102: A45.

4 Eriksen CA, Cullen PT, Sutton D, Kennedy N, Cuschieri A. Abnormal esophageal transit in patients with typical reflux symptoms but normal endoscopic and $\mathrm{pH}$ profiles. Am $\mathcal{f}$ Surg 1991; 161: 657-61.

5 Hewson EG, Sinclair JW, Dalton CB, Wu WC, Castell DO, Richter JE. Acid perfusion test: does it have a role in the assessment of noncardiac chest pain? Gut 1989; 30: 305-10.

6 Hewson EG, Dalton CB, Richter JE. Comparison of esophageal manometry, provocative testing and ambulatory monitoring in patients with unexplained chest pain. Dig Dis Sci 1990; 35: 302-9.

7 Howard PJ, Pryde A, Heading RC. Relationship between gastroesophageal reflux and symptoms in patients referred for ambulatory $\mathrm{pH}$ monitoring. Foumal of Gastrointestinal Motility 1990; 2: 231-9.

8 Johnston BT, McFarland RJ, Collins JSA, Love AHG. Symptom index as a marker of gastro-oesophageal reflux Symptom index as a marker of gastro-0

9 Singh S, Richter JE, Bradley LA, Haile JM. The symptom index. Differential usefulness in suspected acid-related complaints of heartburn and chest pain. Dig Dis Sci 1993; 38: 1402-8.

10 Wiener GJ, Richter JE, Copper JB, Wu WC, Castell DO. The symptom index: a clinically important parameter of ambulatory 24-hour esophageal $\mathrm{pH}$ monitoring. $\mathrm{Am} \mathcal{f}$ Gastroenterol 1988; 83: 358-61.

11 Ward BW, Wu WC, Richter JE, Lui KW, Castell DO. Ambulatory 24-hour oesophageal pH monitoring: technology searching for a clinical application. $f \mathrm{Clin}$ Gastroenterol 1986; 8 (suppl 1): 59-67.

12 Richter JE, Hewson EG, Sinclair JW, Dalton CB. Acid perfusion test and 24-hour esophageal pH monitoring perfusion test and 24-hour esophageal pH monitoring with symptom index. Comparison of tests for

13 Breumelhof R, Smout AJPM. The symptom sensitivity index: a valuable additional parameter in 24-hour index: a valuable additional parameter in 24-hour esophagea $160-4$.

14 Ghillebert G, Janssens J, Vantrappen G, Nevens F, Piessens J. Ambulatory 24 hour intraoesophageal $\mathrm{pH}$ and pressure recordings $\mathrm{v}$ provocation tests in the diagnosis of chest pain of oesophageal origin. Gut 1990; 31: 738-44. 
15 Lam HGT, Breumelhof R, Roelofs JMM, Van Berge Henegouwen GP, Smout AJPM. What is the optimal time window in symptom analysis of 24-hour esophageal pressure and pH data? Dig Dis Sci 1994; 39: 402-9.

16 Howard PJ, Maher L, Pryde A, Heading RC. Symptomatic gastro-oesophageal reflux, abnormal oesophageal acid exposure, and mucosal acid sensitivity are three separate, though related, aspects of gastro-oesophageal reflux disease. Gut 1991; 32: 128-32.

17 Wiener GJ, Morgan TM, Copper JB, Wu WC, Castell DO, Sinclair JW et al Ambulatory 24-hour esophageal $\mathrm{pH}$ monitoring. Reproducibility and variability of $\mathrm{pH}$ parameters. Dig Dis Sci 1988; 33: 1127-33.

18 Colin-Jones DG, Bloom B, Bodemar G, Crean GP, Freston J, Gulger R, et al. Management of dyspepsia: report of a $\mathrm{J}$, Gulger R, et al. Management of dysp

19 Bruley des Varannes S, Galmiche JP. Evaluation of esophageal sensitivity. In: Scarpignato C, Galmiche JP, eds. Functional investigation in esophageal disease. Front Gastrointest Res. Basel: Karger, 1994; 22: 344-65.

20 Baldi F, Ferrarini F, Longanesi A, Ragazzini M, Barbara L. Acid gastroesophageal reflux and symptom occurrence: analysis of some factors influencing their association. Dig Dis Sci 1989; 34: 1890-3.

21 Smith JL, Opekun AR, Larkai E, Graham DY. Sensitivity of the esophageal mucosa to $\mathrm{pH}$ in gastroesophageal reflux disease. Gastroenterology 1989; 96: 683-9.

22 Janssens JPF, Vantrappen G. Irritable esophagus. Am $\mathcal{F}$ Med 1992; 92 (suppl 5A): 27-32S

23 Zerbib F, Bruley des Varannes S, Oriola RC, McDonald J, Isal JP, Galmiche JP. Alosetron does not affect the visceral perception of gastric distension in healthy subjects. perception of gastric distension in
Aliment Pharmacol Ther 1994; 8: 403-7.

24 Marrero JM, de Caestecker JS, Maxwell JD. Effect of famotidine on oesophageal sensitivity in gastrooesophageal reflux disease. Gut 1994; 35: 447-50. 